\title{
Log(ist)ic and simplistic S-curves
}

Link to publication record in Manchester Research Explorer

\section{Citation for published version (APA):}

Denison, D. (2003). Log(ist)ic and simplistic S-curves. In R. Hickey (Ed.), Motives for language change (pp. 54-70). Cambridge University Press.

\section{Published in:}

Motives for language change

\section{Citing this paper}

Please note that where the full-text provided on Manchester Research Explorer is the Author Accepted Manuscript or Proof version this may differ from the final Published version. If citing, it is advised that you check and use the publisher's definitive version.

\section{General rights}

Copyright and moral rights for the publications made accessible in the Research Explorer are retained by the authors and/or other copyright owners and it is a condition of accessing publications that users recognise and abide by the legal requirements associated with these rights.

\section{Takedown policy}

If you believe that this document breaches copyright please refer to the University of Manchester's Takedown Procedures [http://man.ac.uk/04Y6Bo] or contact uml.scholarlycommunications@manchester.ac.uk providing relevant details, so we can investigate your claim.

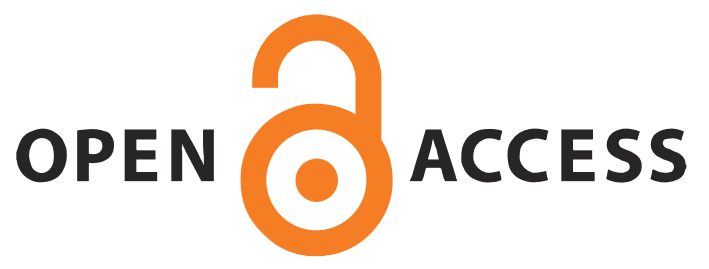


Denison, David. 2003. Log(ist)ic and simplistic S-curves.

In Raymond Hickey (ed.), Motives for language change, 54-70.

Cambridge: Cambridge University Press.

http://www. cambridge.org/gb/knowledge/isbn/item1167892/?site locale=en GB

\section{$4 \quad \log ($ ist)ic and simplistic S-curves}

\section{David Denison}

\section{Introduction}

The technical term $S$-curve goes back at least to 1839 (OED, as two words), and in the context of linguistic change certainly to 1954 (Altmann et al. 1983: 105). The importance of S-curves is now generally taken for granted in historical linguistics. ${ }^{1}$ Devitt, for example, asserts that ' $[\mathrm{t}]$ he $\mathrm{S}$-curve pattern of diffusion occurred throughout [her] data' (1989: 75). Here is a more recent example concerning early Modern English morphosyntax (Nevalainen 2000: 339):

I need to be able to measure the degree of supralocalisation and subsequent standardisation of a linguistic variable. The measure I shall use will be the completion of an $\mathrm{S}$-curve by the feature in question in the data examined.

In Nevalainen's paper, many graphs need just five or six data-points to reveal a jagged but nevertheless recognisably S-shaped form. I myself have long assumed 'that the time course of the propagation of a language change typically follows an S-curve', as Croft expresses it (2000: 183). In this chapter I wish to question why this might be so, what it means and why perhaps, in the end, it is actually rather unexpected. In touching on explanations of language change and notably the shape that changes take, there is a risk (or one might well say, the hope) of echoing some of Roger Lass's published work: there can be few topics in historical linguistics that he has not profitably addressed at some time or other.

Change tends to proceed slowly at first, then after a while it speeds up. That seems uncontroversial enough. Linguistic change is always occasional

* I first started reflecting on S-curves in Denison (1999), a lecture delivered at a conference on medieval English under the title 'Slow, slow, quick, quick, slow'. This chapter is in part a reworking of that paper. I have developed the discussion of S-curves proper and compressed some speculations about the overall chronological shape of change in English. I am grateful to Helena Raumolin-Brunberg for some references and for her friendly and stimulating disagreement, to Ted Briscoe for two preprints, to Edmund Weiner of the $O E D$ for looking into early uses of the term $S$-curve, and to Malcolm Campbell for help with graphics.

1 Helena Raumolin-Brunberg (personal communication, 19 Sept. 2000) wryly implies, however, that relatively few S-curves of long-term historical data are actually available, apart from graphs based on Ellegård's famous Do material (1953). 
and sporadic to begin with. We might imagine plotting some imaginary change as in (1), where at first only the conservative form is found, so that the proportion of an innovatory form (as against the conservative form) is zero. After the first occurrence, the curve slowly climbs through single-figure percentages until the innovation is being used on maybe 20-25 per cent of the available occasions (20 per cent is the usual transition point chosen in such illustrations). All the time its rate of increase is increasing - the curve is getting steeper - and after a while its progress is very rapid:

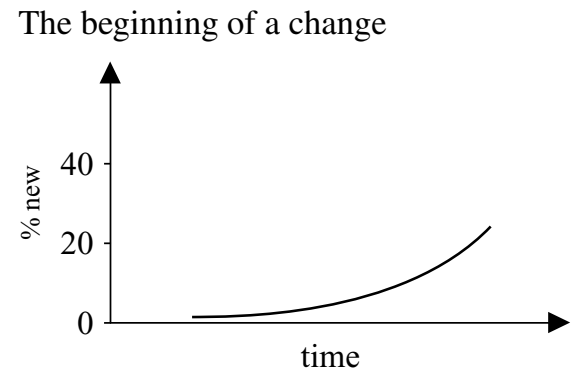

Why has the rate of change been speeding up? What happens next? A commonsense view might be that we make our linguistic choices by analogy, modelling our behaviour on what we hear around us. A change must start somewhere. Use with one word - for a change which can be located at word level, such as a sound change - might eventually be generalised to a second, then to a third, and so on, and as the number of relevant words showing the change and acting as models reaches a 'critical mass', it makes sense that the remainder should be drawn into the change with increasing speed. The rate goes on increasing until the remaining pool of unchanged words is altogether used up. 'Critical mass' is the imagery of nuclear fission. It suggests that linguistic change ought to go 'slow, slow, quick, quicker, bang!', something like (2):

(2)

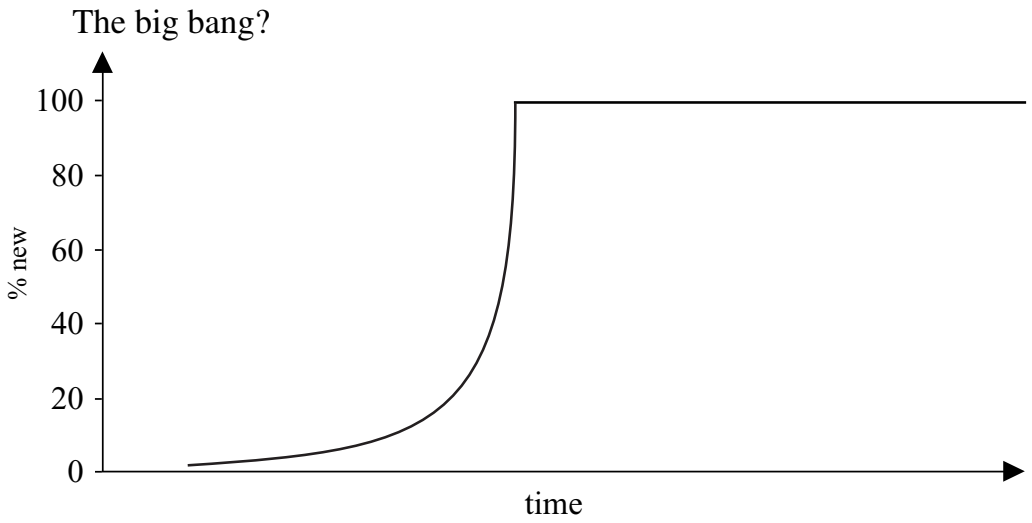


In diagram (2), the rate of change rises exponentially until the new form completely ousts the old. Of course, you can't use a form on more than 100 per cent of the available occasions, so when the proportion hits 100 per cent, the curve just becomes a horizontal line again.

Trouble is, this does not generally happen. Our common-sense thought experiment does not seem to reflect linguistic history very well at all. What actually happens much of the time is more like 'slow, slow, quick, quick, slow'. After the phase when the new form gains ascendancy rather rapidly, the process of change slows down again as the last remnants of the older state linger on. The result might look something like this:

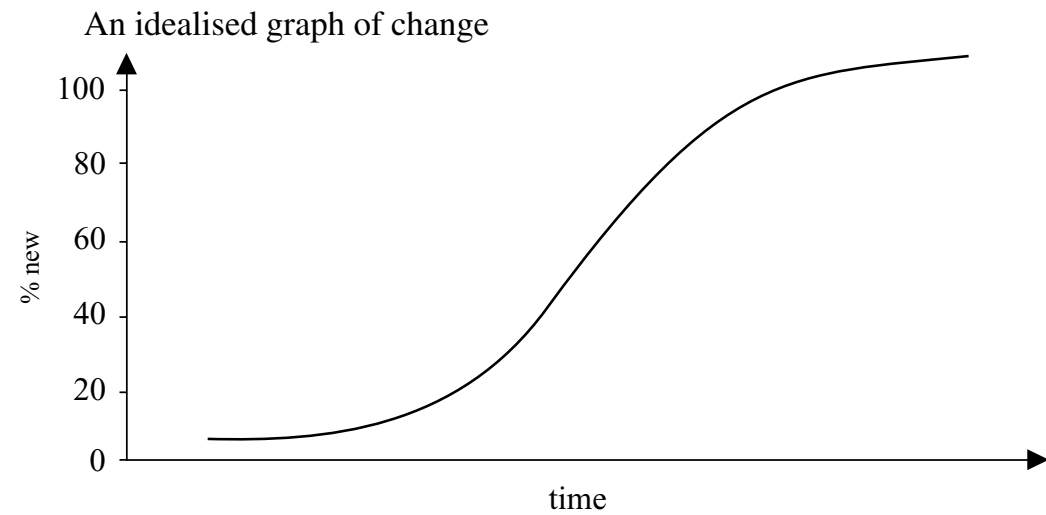

The whole thing can last hundreds of years altogether, indeed may never be wholly completed, but the bulk of the change is located within a much narrower slice of time where the slope is steeper. We need a concrete example.

The standard reference works (see Denison 1993: 428) all point to 1795 as the date of the earliest occurrence of the English progressive passive, as in the modern type:

A road was being built.

Then there is a rash of further occurrences in the decades immediately following. The construction seems to spring rather quickly into use, albeit at first a rather limited and socially constrained use. Earlier examples keep turning up, however: ${ }^{2}$

(5) I have received the speech and address of the House of Lords; probably, that of the House of Commons was being debated when the post went out. (1772)

\footnotetext{
2 Examples (5) and (6) are due to Roger Higgins (via Warner 1995), and (7) to Linda van Bergen (personal communication, 27 Oct. 1999).
} 
(6) The inhabitants of Plymouth are under arms, and everything is being done that can be. (1779)

and while you are being lampoon'd in ballads and newspapers, I mean to cut a figure in the history of England (1790)

Nakamura (1998) claimed to have a seventeenth-century example, which I do not find convincing, and in Denison (1999: 54) I toyed with an apparent example from 1709 which subsequently proved to be a modern editorial creation. In a way that makes the point. What it strongly suggests is that if enough suitable texts had survived from the eighteenth and maybe also the seventeenth centuries, and if we had the resources to go through them all, we might well be able to show the characteristic early life of a linguistic innovation, with occasional, sporadic occurrences leading eventually to a more rapid take-up. Early use of the progressive passive is sporadic, and the very earliest one might be ca 1770, like (5), or some earlier date. It doesn't matter too much (at least for this kind of story.) But I am sure the beginning of the steeper part of the rise would be in the late 1790s and early 1800s. In Pratt and Denison (2000) we have tried to give a sociohistorical account of this period (and I have also speculated on a possible regional origin for the construction).

That is the transition from 'slow, slow' to 'quick, quick': I have chosen this example to illustrate an S-curve, because in this instance we would probably be justified in going on to complete a whole graph like that in (3), since arguably there were old and new forms in genuine competition:

A road was building.

$$
\text { (=(4)) A road was being built. }
$$

Unusually in syntax, these are forms which seem to be virtually synonymous. Between the late eighteenth century and the present day, type (8) has been replaced by type (9), at first occasionally, then in the mid to late nineteenth century with great rapidity. In fact Nakamura (1998) judges from his evidence of diaries and journals that the majority usage was already type (9) for people born after 1800 , therefore leaving written records after the 1820 s or so. However, type (8) did not die out in the nineteenth century:

(10) A trans-provincial highway is building through southern British Columbia from the mountains ... to Hope in the Fraser River Valley. (1916 [OED])

Sporadic examples continue to be found. The speed of change returns from 'quick, quick' to 'slow' again, and the (8) type, sometimes known as the passival, may never quite die out. 


\section{$2 \quad$ Why an S-shaped curve?}

Why do we get S-curves rather than big bangs? The case which is usually made (see e.g. Labov 1994: 65-6, who traces it back to Bloomfield) runs roughly as follows. That rush to follow analogy is utterly misleading, since we are dealing here with gradual processes which take a long time to go through, even in the rapid phase. It's much more like evolution by natural selection, where repeated minuscule statistical preferences gradually add up over the generations to a large cumulative difference. Change requires variation, the existence of an alternative way of saying roughly the same thing. There would be no change at all unless there were some small advantage in the new form, whether structural or social. The net advantage of the new form must be small, as - if for no other reason - inertia and the need to communicate with older generations mean that the old form has something going for it as well. The change proper gets goingthe transition from innovation to propagation - if the new form acquires a social value (Croft 2000: 185-6).

Now, speakers reproduce approximately what they hear, including variation, and even apparently including the rough proportions of variant usage they hear around them. ${ }^{3}$ However, if there is some slight advantage in the new form over the old, the proportions may adjust slightly in favour of the new. Thus the status quo is not reproduced with perfect fidelity. The speaker has (unconsciously) made a slightly different choice between variants - albeit a statistical choice, reflected in frequencies of occurrence. And this effect of choice is greatest when the two variants are both there to choose from. In the very early stages of a change, so the argument runs, the new form is rare, so the pressures of choice are relatively weak and the rate of change is slow. In the late stages of a change, the old form is rare, so that the selective effect of having two forms to compare and choose between is again weak, and once again the rate of change is slow. Only in the middle period, when there are substantial numbers of each form in competition, does the rate of change speed up. Hence the S-curve.

What of the mathematics? Labov shows how an S-curve is produced by the cumulative frequencies of the binomial distribution (1994: 65). He mentions too that other mathematical functions have this shape, including the cumulative normal distribution and the logistic function. Altmann et al. had looked at three different functions that produced similar S-shaped curves, preferring the logistic function, in which the rate of change is proportional to the frequencies both of old forms and new (1983: 106-9) - cf. the plausibility argument above. Kroch also uses the logistic to model linguistic S-curves (1989a, b, etc.), arguing that it provides a good empirical fit, that its mathematics are simple, and that in the possibly analogous case of population biology, the logistic can actually be derived theoretically from one particular proposal for a mechanism of change.

\footnotetext{
${ }^{3}$ Labov talks of probability matching (1994: 580-6, also cf. 1994: 65-6, 595), an interesting concept which I cannot go into here.
} 
Niyogi and Berwick are more cautious, or perhaps more catholic, in their choice of mathematical function (1997: 715):

We note that...the logistic shape has sometimes been assumed as a starting point, see, e.g., Kroch [(1989b)] ... On the contrary, we propose that language learning (or mislearning due to misconvergence) could be the engine driving language change. The nature of evolutionary behavior need not be logistic... Sometimes the trajectories are S-shaped (often associated with logistic growth); but sometimes not ...

Briscoe (2000a) reviews some models of population, speaker-hearer interactions and language learning. The assumptions made can sometimes lead to logistic or logistic-like diffusion of an innovating grammar through a population. Note too that the term logistic may also be used for distributions of S-shaped appearance, without commitment to the underlying mathematics.

Of course the scenario I sketched out a little earlier is merely another thought experiment, but the suggested time course of change with its distinct phases does seem to correspond to observable facts. We know from experience that we don't suddenly wake up one morning and find that everyone is using a novel syntactic construction or pronouncing the diphthong/eI/ differently. Even successful innovation takes time to catch on. As for the 'quick, quick' phase of the main part of a change, there are examples where the rate of increase in frequency is sharp enough to be perceptible; I think here of the rapid growth of non-present-tense may in the last couple of decades, most notoriously in the form of counterfactual may have at the expense of traditional might have:

(11) I suppose history may have been different had we done so, or had we entered at a different rate or discussed the rate with others when we entered (1999 Chris Patten, The Guardian Saturday Review, p. 9 (16 Oct.))

And we know that there are often stubborn relic forms left over 'after' language change: think of the remaining irregular plurals in Modern English (children, feet, deer, etc.) when nearly all other nouns have gone over to a single regular pattern, or the fossil syntax of such PPs as the whole world over after the general loss of post-positional prepositions.

\section{The axes of the graph}

However, not everything about S-curves is clear to me. I want now to turn to the vertical scale in those hypothetical graphs. What are the percentages percentages of? There are a number of possible answers to this question.

The percentages could be percentages of relevant linguistic contexts in some corpus (ideally in all speech events in the whole language during the relevant period, though of course we could never observe them). There are all sorts of different linguistic contexts we could use to subdivide this potentially huge mass of data. For example, some changes are supposed to spread by lexical 
diffusion, that is, word by word through the relevant lexemes of the language. Labov argues that some (not all) sound changes work like that, namely those involving 'the abrupt substitution of one phoneme for another' such that the newer form 'will usually differ by several phonetic features' from the older (1994: 543), while Lass (1997: $141 \mathrm{n}$. 41) suggests that all phonological change at least starts with lexical diffusion. ${ }^{4}$ Then we would be counting proportions of the relevant words which have succumbed to the change at a given time.

Suppose that the small impetus towards change has to do with some structural disadvantage in the old form (Labov: 'a tendency for one or the other type of form to be misunderstood more than the other', 1994: 586), then after the change had taken place in a majority of contexts, reduction in numbers of the old form would perhaps reduce the pressure for change, allowing the rate of transfer to the new form to slow down again. Or words that are particularly salient, or maybe especially frequent or infrequent, or of a particular form, might resist the change for reasons which had not applied - or at least did not apply so strongly - to those words which had succumbed early on. Even if the impetus towards change is not structural but to do with social convention (Croft: 'the desire of hearers to identify with the community to which [a speaker of particular variants] belongs', 2000: 183), then according to Labov (1994: 66) there would still be the same slow-down towards the end.

However, lexical diffusion is not the only kind of diffusion through linguistic space. Another example would be the spread of a syntactic change through particular construction types, though that could hardly be plotted as a percentage. Let's return to the question of the vertical axis in an S-curve of change.

Pragmatic contexts present a special case of linguistic context, slightly outside the more structured systems of phonology, lexis, syntax, etc. Percentages don't seem so appropriate here either, as it seems strange to try to enumerate the registers, but the informal principle of spread 'through the language', register by register, has some intuitive appeal. Suppose the new usage begins life as merely a private family usage, or as slang, or as a colloquialism, for instance. If it generalises beyond its original context, it might be expected to appear next in a related register, and so to spread through the language. Again, from 'slow, slow' to 'quick, quick' is easy to motivate, but back to 'slow' again needs reasoning which may be (in every sense) slightly post hoc, probably to do with salience: the last to go on resisting a change from above would be the least salient contexts, and in change from below, perhaps the most salient. For the concept of changes from above/below as both social and mental phenomena, see Labov (1994: 78).

\footnotetext{
${ }^{4}$ Note that Labov claims that the process of lexical diffusion - as opposed to regular sound change 'is most characteristic of the late [my italics: DD] stages of an internal change ... or of borrowings from other systems ("change from above")' (1994: 543).
} 
Variation is very common in the speech of an individual. Some of that variation may depend on individual lexemes or on particular linguistic contexts, as already discussed. However, there is also sometimes an element of statistical variation for which no direct link can be established to any particular conditioning factor. For a given word in a given context, the speaker may use one form on X\% of available occasions, and another form for the remainder - orderly heterogeneity. Perhaps this means that there is some subtle conditioning factor or constellation of factors which has not yet been identified by scholars, or perhaps it's an irreducibly random choice with an overall statistical pattern, like radioactive decay. This kind of variation is the staple of Labovian sociolinguistics. The question then arises, does an individual's usage change as he or she gets older, or is overall change through time in a language merely a function of changes in the population, with older speakers becoming inactive and dying, and younger speakers continually entering the community? I believe that speakers do change their usage during adult life (see now Croft 2000: 48-9, 55-9 for some discussion), so that language change has an individual as well as a social component, but I do not know whether the former typically follows an S-curve. S-curves of linguistic change would not normally be plotted through the lifetime of an individual speaker (outside language acquisition studies, anyway), as scholarly practice is to produce composites of the usage of many speakers (or writers).

Chambers thinks that one kind of change in the individual does involve an S-curve. He cites the phenomenon (1992: 695) in connection with his study of six Canadian youngsters acquiring Southern England English:

The typical pattern ... is the S-curve, with phonological changes occurring slowly for the first $20 \%$ or so of possible instances and then rising rapidly to about $80 \%$ before tailing off towards categoricity. The empirical basis underlying the S-curve is the sparsity of speakers caught in the middle three fifths, $20-80 \%$, at any given time, in contrast to the clusters of speakers found at either end. These figures are taken to signify that speakers must sporadically acquire new pronunciations for about $20 \%$ of the available instances as the basis for generalizing a rule, and that, once the process becomes rule-governed, about $80 \%$ of the instances will be affected immediately, with some portion of the remaining instances, usually the less frequent ones (Phillips 1984), resisting change and perhaps remaining as residue.

Here a synchronic (apparent time) distribution of speakers with respect to some complex rule is apparently assumed to correspond diachronically to the time course of the adoption or dropping of that rule. This, then, is a very different explanation from Labov's for the S-curve, depending as it does not on statistical competition between variants but on catastrophic (in the Thomian sense) reorganisation of a speaker's internal grammar, much more along the lines promoted by Lightfoot for syntactic change in general and - though with a much more functionalist bias - by Stein for a syntactic change dependent on 
phonology (1990: 218-20, 300-1). Some recent work tends to abstract away from observed usage and envisage the spread of grammars through a population, thus e.g. Briscoe (2000a, b). There is disagreement as to whether an individual may have access to more than one grammar at a time. For further discussion of differing interpretations of the relationship between an individual's usage and S-curves see also Croft (2000: 187-8).

If we consider communities of speakers we have some more explicit modelling of language contact between individuals, notably Lesley and James Milroy's ideas about social networks (e.g. L. Milroy 1987; J. Milroy 1993). So there can be propagation via weak ties between social networks, and inhibition of change by strong ties within a social network. We need some mechanism for tying such models of social contact into the arguments about selectional pressure. Percentages could be the proportions of speakers in the community at any time who show (at least some? majority? invariable?) usage of the new form.

What constitutes a community is an interesting question. Are we, for instance, looking at the relatively small numbers of interlocutors in a local social network, or the whole population of medieval England, grown to some 4-5 million by renaissance times, or the hundreds of millions of current speakers of English world-wide? Croft has some comments on the natures of different types of community (2000: 187). I note that Briscoe uses relatively small population sizes in his computer simulations of language change because 'networks of strong and regular linguistic interaction are probably limited to group sizes of around 100-150' (2000a: 7). Grouping historical data may reveal overall trends; equally, lumping disparate data together may conceal the true path of change. Thus, for example, Kroch and Taylor's explanation of verb-second syntax (1997) depends crucially on separate treatment of certain Middle English dialects.

For completeness I should point out that the horizontal scale is not without controversy. Does one plot the data against the time of composition (or writing), or is the relevant time the birthdate of the writer? This question is clearly connected to our previous discussion of whether language development continues during the adulthood of speakers - or rather, how significant such development is when set against the norms established in childhood and adolescence. ${ }^{5}$

\section{$4 \quad$ Syntactic illustrations}

We see, then, that there are various different senses in which a change could be said to have the shape of an S-curve. I turn now to some illustrations from the

5 The $x$-axis need not even represent time at all. Devitt changes it at one point to texts (1989: 38-46), arranged so as to get a monotonic rise in frequencies of the innovating form. If the resulting graph is $\mathrm{S}$-shaped, she claims it represents diffusion in apparent time across speakers. 
history of English of certain points of view I have mentioned, mainly using the syntactic data with which I am most familiar.

Many years ago I argued that a syntactic innovation, the prepositional passive, spread by lexical diffusion. That is the very characteristic English construction seen in

Fran will be frowned at

first found in the thirteenth century. One piece of evidence for lexical diffusion concerned a particular prepositional verb, LETEN of 'think of, regard'. Both the verbal part and the preposition in LETEN of had idiosyncrasies which made that particular combination a likely point of entry for the new passive construction (see Denison 1993: 141-3), even if the very earliest attested prepositional passive happens to involve a different item. If the construction did indeed spread by lexical diffusion, an obvious route would be from LETEN of to the closely related prepositional verbs LETEN $b y$, SETTEN $o f / b y$, TELLEN of $/ b y$, all of which mean 'regard, esteem, think of', and all of which are semantically and even phonologically similar. Sure enough, all of these combinations are prominent among the early examples:

no prophete is so mychel leten of in his owene cuntre as... (ca 1400) 'No prophet is so well regarded in his own country as...'

Visser lists by century the prepositional verbs which permit such passives (1963-73: §§1947-57). Allowing for his errors, by 1300 there was one such verb, by 1400 another 22, by 1500 another 64, and so on. If we count by type (particular combinations), then, we get the lower half of an S-curve, and the same would be true if we counted by token (actual examples), though here we would be plotting absolute numbers rather than relative frequencies. It isn't clear what 'completion of the change' could be, however, short of every conceivable verb-preposition combination having a passive, or - better - every one with appropriate semantic roles for its nominal arguments (which in any case is not an invariant set), so I am unwilling to attempt the upper half of the S. More important, this would not be an S-curve based on proportion and therefore on the notion of competition between variants, but one based on absolute frequency; the underlying mathematics of such a graph are quite different.

Having looked at a change with perhaps only the first half of an S-curve, I can refer to the recent paper by Cynthia Allen (2000) which examined the alleged suddenness of the change in the twelfth century by which verb-final order was lost from English. The upshot of her analysis is that there is no good evidence of 'sudden death', and that gradual obsolescence was at least as plausible a scenario. This would be the second half of an S-curve, and one where competition between variants is plausible. It is probably the case that complete or near-complete S-curves are outnumbered by changes which show 
just part of the S-curve, whether the part-curves result from the impossibility of obtaining numerical evidence or from disruption or reversal of a change.

Another ME innovation is periphrastic Do, the use of Do as a dummy auxiliary verb with the infinitive of a lexical verb, first found (in my opinion) in the thirteenth century:

toward pe stude pat pe sonne In winter doth a-rise. (ca 1300)

'towards the place that the sun in winter does arise'

A paper by Ogura (1993) has argued that lexical diffusion is the route for the spread of this construction through the language, whereas Kroch (1989a, b, etc.) has argued that the right way to visualise the spread of the construction is not verb by verb but syntactic context by syntactic context. I don't propose to get involved in that particular disagreement. Both are compatible with an S-curve. Kroch's approach has a number of interesting consequences for us:

- he employs a mathematical transformation of one kind of S-curve which allows one to develop a measure of rate of change and perhaps of startingpoint;

- he finds that the S-curves for different syntactic contexts (e.g. interrogatives, negatives) show the same rate of change, his so-called Constant Rate Hypothesis;

- he finds that the S-curves for Do in different syntactic contexts show discontinuities in the late sixteenth century - something which for him demands an explanation in terms of syntactic restructuring at that time;

- the frequency of affirmative declaratives starts off as it should with a slow rise, but then rather than accelerating up an S-curve it dies away again until it has virtually disappeared from the language by 1800 - which shows that not all changes proceed irreversibly; presumably the steady favouring impetus had disappeared.

For diffusion through pragmatic contexts, we might consider some other scholarly writings on periphrastic Do, for example the contention that in Chaucer's English it was particularly appropriate for use with children (Tieken-Boon van Ostade 1990), which I am unconvinced about, or work by Rissanen (1991, etc.) and others on the registers in which the periphrasis occurs at different periods. For recent and subtle analysis of Ellegård's (1953) figures see Warner's ongoing work (2000), and for revision of the data Nurmi (2000).

Finally, back to society. Labov and his followers have given myriad examples of diffusion of linguistic change through the strata of a modern society. Various scholars from Helsinki have begun to demonstrate it from a period of around five to three centuries ago with the Corpus of Early English Correspondence project. Going back earlier still, we can mention something like the replacement of native forms like hi, her(e) and hem by the Scandinavioid personal pronouns they, their and them, a development which involves both lexical and 
geographical diffusion. Lexical because they typically appear in a given dialect area in the order subjective, then genitive, and last of all objective, and geographical because over time the isoglosses which divide old and new forms on the map move southwards. Geographical diffusion through the country can be seen as an example of spread through the community of speakers, though to treat the England of Middle English as a single speech community is perhaps a bit dubious.

\section{$5 \quad$ Variables and variants}

I do have other problems with S-curves. The original justification for them was the ecological competition between two variants competing to perform the same linguistic function. Immediately we have problems with sound changes in the vowel space, where at the phonetic level at least there is the possibility of continuous variation and hence no two competitors. This can perhaps be tackled at the phonological level with some kind of feature analysis which allows an abstraction away from the analogue kind of continuous change to a quantised stepping between discrete states. In Lass's discussion of the size of such quanta is the claim that 'the units of change are generally very small (though not of course infinitely so)' (1997: 222), which would militate against simple binary competition lasting over a long time period. But even with the syntactic phenomena I am more at home with, it is a rarity to find competition between one old form and a single replacing form. Let me review some of my examples in this connection.

Progressive passive. Types (8) and (9) are close to being a binary choice, but there were also other means of expression, including actives, non-progressive passives, and so on.

Counterfactual may have. The may have of (11) begins to replace might have, but could have is a third possibility in some positive contexts:

(15) How different her own life might have been if she'd had a brother a 'bro' who may have grown up to be bigger and stronger than Dad, who could have put a stop to the violence. (2000 Anna Davis, Melting (Sceptre), 152)

Example (15) is a convenient one to cite because it shows alternation between might have and may have in an epistemic context, but also has could have in a clause with a possible epistemic reading beside its deontic one. Note, however, that because of scope differences, could have is not an alternative to might/may have in negatives, so that the number of variants available depends crucially on the syntactic context. 
Prepositional passive. If type (12) was an innovation, what did it replace? An active with the indefinite pronoun man or me as subject? That is indeed a close equivalent in function to a passive, but it wasn't the only one, and after the fifteenth century it was no longer in contention, yet the prepositional passive continued to spread.

Periphrastic Do. The innovation of type (14) is mainly in competition with simple tensed forms, but it only gives part of the picture of the history of the periphrasis if - as is often done - the only clauses counted are those with no auxiliary or with Do, since the other auxiliaries are changing in frequency as well. I demonstrated in Denison (1993: 467-8) that even before periphrastic Do had become common, negatives showed a statistically significant preference for the presence of an 'operator' (broadly, an auxiliary verb or main-verb BE or HAVE) over the use of a simple lexical verb alone.

Just as gravitational attraction between two bodies is easier to calculate than the so-called three-body problem, so competition between two variants is easier to model than competition among three or more. In linguistic work, at least, I am not aware of serious attempts to model competition among multiple variants. Even a work like Niyogi and Berwick (1998) which plots three-dimensional graphs of dynamical systems is doing so only as part of an attempt to model systems with two linguistic variants. Nevalainen explicitly mentions that one of her case studies of standardisation, the spread of present indicative plural are at the expense of the older be, ignores a third variant, plural is (2000: 342). ${ }^{6}$

Here is another question as yet unresolved for me, also concerned with the number of variants under consideration. Consider the advent of the form of used in positions where traditional grammar demands have. This is now increasingly common. If we plot written language, we can treat have and of as old and new variants, respectively, and very probably find the lower half of an S-curve relating their use. (I have not done this: it would demand a major corpus investigation of extremely common forms in so-far untagged material.) The earliest example I have found, (16), is a little isolated chronologically from the early cases noted in $O E D$ s.v. of joc. '(being erroneous in Received Standard) or dial. var. HAVE v.', (17)-(18) (and, why, incidentally, must all instances be 'jocular'?):

(16) Had I known of your illness I should not of written in such fiery phrase in my first Letter. (1819)

(17) Soposing seven hundred and sixty [servants] to of advertised and the same number not to of advertised. (1837 [OED])

(18) I never would of married in the world, ef I couldn't of got jist exactly suited. (1844 [OED])

\footnotetext{
6 Raumolin-Brunberg points out that she and Nevalainen have also sometimes created a binary opposition by plotting the innovative form against all the others (personal communication, 19 Sept. 2000)
} 
This is the typical sporadic, slow start of an innovation, and it should be possible in principle to plot the increasing proportion of of in written texts. There remains the question of whether to treat contracted 've as representing have or as a third variant. But the real problem comes if we try to plot the history of these forms in recent speech, where - I would guess - unstressed [əv] would vastly outnumber both [hæv] and [ov] and yet couldn't in any individual case be ascribed with confidence to either the conservative or the innovative underlying form. The existence of the unstressed [əv] form is probably crucial to the development of stressed [Dv] in such patterns, precisely because it is equivocal, and its high frequency is part of its importance. To ignore the equivocal examples would therefore be a gross distortion of the evidence, and yet they could not be counted either as old or new.

Another problem with S-curves is that of synonymy: are we entitled to treat variants as members of a single variable, that is, as equivalent alternative expressions of 'the same thing'? Outside the realms of phonology, perhaps morphology and just possibly lexis, that is very much a moot point. To call two syntactic forms fully equivalent is to make a very bold claim indeed. The pioneering investigations of the Helsinki sociolinguists rely perhaps on selecting changes which can plausibly be reduced to competition between two variants. I wonder how often this can be done.

\section{Conflation of S-curves: the shape of English}

We could start to pull the camera outwards and backwards. Diffusion of a syntactic change through different words and/or contexts could be looked at from afar as the overall progress of that change in the language. (Aitchison (1991: 85-7) suggests that S-curves for a given change tend to be made up of overlapping little S-curves, each representing one linguistic environment.) It makes language change sound rather like a fractal, in that it might be self-similar at any magnification, though probably not in other aspects of the mathematical functions which can model language change. Maybe if we moved even further away, all the syntactic changes could be subsumed into one big curve, all the sound changes into one big curve, then linguistic changes of all kinds into one big change. Maybe the history of the English language is, crudely speaking, one big S-curve.

That may sound silly: no percentage scale would make any sense if you tried to conflate different changes into a single curve. What I had in mind was superposing a number of graphs to see where they bunch in historical time, rather like looking at isoglosses in the hope of spotting a significant dialect boundary. And rather than the S-curves themselves, peak values of the rate of change (first differential of the S-curve) would have to be plotted to see whether they tend to coincide. This whimsical idea of gathering together a lot of S-curves came about because in playing with the 'slow, slow, quick, quick, 
slow' catch-phrase, I realised that it is often applied implicitly to the shape of the English language as a whole, under the frequently made assumption that Old English and (late) Modern English are relatively invariant, whereas Middle (and possibly early Modern) English show rapid change of all kinds.

Does such a view stand up to examination? Immediately we run up against the problem of periodisation (Blake 1994, and see now also Lass 2001). Old English did not spring fully armed out of nowhere in about 700; it came at the end of a long period of Germanic development which can be reconstructed in many respects with great certainty. Most of the extensive surviving writings either come from the narrow early West Saxon or late West Saxon bands, or they are later copyings of earlier texts. And the transition to early Middle English is masked by a paucity of surviving texts from the crucial time. The geographical spread of the documents is also very patchy, with later documents like the essential Second Continuation of the Peterborough Chronicle, or Ormulum, not corresponding very well to anything much in Old English. Furthermore, we might well argue that in many respects, the later Middle English and the early Modern English periods (under their standard labels) really belong together, for example as far as phonology, morphology and even syntax are concerned. Undiluted, unmodernised Shakespeare is not an easy read for present-day schoolchildren.

Having made those obvious cautionary noises, I then tried in Denison (1999) to separate the major domains of linguistic study, and drew the conclusion that for many of them Middle English was not a specially active period of change, apart perhaps from nominal morphology and lexis. Roger Lass wrote (1997: 304) that 'Languages may vary all the time, but they change in bursts.' Although I'm happy to accept that general statement, on balance I think it's unhelpful to apply it to a whole period of English like Middle English - some 400 years and to every domain of linguistics.

\section{$7 \quad$ Concluding remark}

The catch-phrase 'slow, slow, quick, quick, slow' refers, I gather, to the fox-trot. Here's what one of the $O E D$ 's citations has to say about that dance:

The Fox-Trot is a dance of many steps, and to the casual observer everybody seems to have different ones. (1919 [OED])

Much the same goes for S-curves and the scholars who draw them. The S-curve is neither as simple nor as uniform a phenomenon as is sometimes assumed. Given too the simplistic picture of variation it sometimes reflects (and requires), the S-curve should not be seized on too readily as the general shape of language change. 


\section{REFERENCES}

Aitchison, Jean. 1991. Language change: progress or decay?, 2nd edition. Cambridge University Press.

Allen, Cynthia L. 2000. 'Obsolescence and sudden death in syntax: the decline of verbfinal order in early Middle English', in Bermúdez-Otero et al. (eds.), 3-25.

Altmann, Gabriel, H. von Buttlar, W. Rott and U. Strauss. 1983. 'A law of change in language', in B. Brainerd (ed.), Historical linguistics. Quantitative Linguistics 18. Bochum: Brockmeyer, 104-15.

Bermúdez-Otero, Ricardo, David Denison, Richard M. Hogg, C. B. McCully (eds.). 2000. Generative theory and corpus studies: a dialogue from 10 ICEHL. Topics in English Linguistics 31. Berlin and New York: Mouton de Gruyter.

Blake, Norman F. 1994. 'Premisses and periods in a history of English', in Francisco Fernández, Miguel Fuster and Juan José Calvo (eds.), English historical linguistics 1992: papers from the 7th International Conference on English Historical Linguistics, Valencia, 22-26 September 1992. Current Issues in Linguistic Theory 113. Amsterdam and Philadelphia: John Benjamins, 37-46.

Briscoe, Ted. 2000a. 'An evolutionary approach to (logistic-like) language change', MS, Computer Laboratory, University of Cambridge.

Briscoe, Ted. 2000b. 'Evolutionary perspectives on diachronic syntax', in Susan Pintzuk, George Tsoulas and Anthony Warner (eds.), Diachronic syntax: models and mechanisms. Oxford University Press, 75-105.

Chambers, J. K. 1992. 'Dialect acquisition', Language 68: 673-705.

Croft, William. 2000. Explaining language change: an evolutionary approach. Longman Linguistics Library. London and New York: Longman.

Denison, David. 1993. English historical syntax: verbal constructions. Longman Linguistics Library. London and New York: Longman.

Denison, David. 1999. 'Slow, slow, quick, quick, slow: the dance of language change?', in Ana Bringas López et al. (eds.), 'Woonderous Anglissce’: SELIM Studies in Medieval English Language. Vigo: Universidade de Vigo (Servicio de Publicacións), 51-64.

Devitt, Amy J. 1989. Standardizing written English: diffusion in the case of Scotland, 1520-1659. Cambridge University Press.

Ellegård, Alvar. 1953. The auxiliary 'do': the establishment and regulation of its growth in English. Gothenburg Studies in English 2. Stockholm: Almqvist and Wiksell.

Kroch, Anthony S. 1989a. 'Function and grammar in the history of English: periphrastic do', in Ralph Fasold and Deborah Schiffrin (eds.), Language change and variation. Current Issues in Linguistic Theory 52. Amsterdam and Philadelphia: John Benjamins, 132-72.

Kroch, Anthony S. 1989b. 'Reflexes of grammar in patterns of language change', Language Variation and Change 1: 199-244.

Kroch, Anthony and Ann Taylor. 1997. 'Verb movement in Old and Middle English: dialect variation and language contact', in Ans van Kemenade and Nigel Vincent (eds.), Parameters of morphosyntactic change. Cambridge University Press, 297-325.

Labov, William. 1994. Principles of linguistic change, vol. 1: Internal factors. Language in Society. Oxford and Cambridge, MA: Blackwell.

Lass, Roger. 1997. Historical linguistics and language change. Cambridge Studies in Linguistics 81. Cambridge University Press. 
Lass, Roger. 2001. 'Language periodization and the concept "middle", in Irma Taavitsainen, Terttu Nevalainen, Päivi Pahta and Matti Rissanen (eds.), Placing Middle English in context. Topics in English Linguistics 35. Berlin and New York: Mouton de Gruyter, 7-41.

Milroy, James. 1993. 'On the social origins of language change', in Charles Jones (ed.), Historical linguistics: problems and perspectives. London and New York: Longman, 215-36.

Milroy, Lesley. 1987. Language and social networks, 2nd edition. Language in Society 2. Oxford: Blackwell.

Nakamura, Fujio. 1998. 'A word on the history of the English passive progressive', paper read at the 10th International Conference on Historical Linguistics, Manchester.

Nevalainen, Terttu. 2000. 'Processes of supralocalisation and the rise of Standard English in the early Modern period', in Bermúdez-Otero et al. (eds.), 329-71.

Niyogi, Partha and Robert C. Berwick. 1997. 'A dynamical systems model of language change', Linguistics and Philosophy 20: 697-719.

Niyogi, Partha and Robert C. Berwick. 1998. 'The logical problem of language change: a case study of European Portuguese', Syntax 1: 192-205.

Nurmi, Arja. 2000. 'The rise and fall of periphrastic Do in early Modern English, or "Howe the Scotts will declare themselv's", in Bermúdez-Otero et al. (eds.), 373-94.

Ogura, Mieko. 1993. 'The development of periphrastic do in English: a case of lexical diffusion in syntax', Diachronica 10: 51-85.

Phillips, Betty. 1984. 'Word frequency and the actuation of sound change', Language 60: 320-42.

Pratt, Lynda and David Denison. 2000. 'The language of the Southey-Coleridge circle', Language Sciences 22: 401-22.

Rissanen, Matti. 1991. 'Spoken language and the history of do-periphrasis', in Dieter Kastovsky (ed.), Historical English syntax. Topics in English Linguistics 2. Berlin and New York: Mouton de Gruyter, 321-42.

Simpson, John A. and Edmund S. C. Weiner. 1992. OED = The Oxford English Dictionary: CD-ROM Version, 2nd edition. Oxford University Press.

Stein, Dieter. 1990. The semantics of syntactic change: aspects of the evolution of 'do' in English. Trends in Linguistics/Studies and Monographs 47. Berlin and NewYork: Mouton de Gruyter.

Tieken-Boon van Ostade, Ingrid. 1990. 'The origin and development of periphrastic auxiliary $d o$ : a case of destigmatisation', NOWELE 16: 3-52 [originally published in Dutch Working Papers in English Language and Linguistics 3, 1988].

Visser, F. Th. 1963-73. An historical syntax of the English language, 4 vols. Leiden: E. J. Brill.

Warner, Anthony R. 1995. 'Predicting the progressive passive: parametric change within a lexicalist framework', Language 71: 533-57.

Warner, Anthony R. 2000. 'Change and rate of change in $d o$ ', plenary lecture given at the 11th International Conference on English Historical Linguistics, Santiago. 